\title{
Towards assessing the networkability of health care providers: a maturity model approach
}

\author{
René Fitterer · Peter Rohner
}

Received: 22 September 2008/Revised: 11 April 2009/Accepted: 31 July 2009/

Published online: 19 August 2009

(C) Springer-Verlag 2009

\begin{abstract}
This paper presents a networkability maturity model as an approach to assess a health care organisation's capacity with regards to being able to efficiently engage in business relationships. Continuously rising costs and increasingly restrained budgets for health care put pressure on the public health systems. A low division of labour and integration of processes along cross-organisational patient therapy provides large potential for improvements in efficiency and efficacy. It is the aim of the presented model to enable identification of potentials for improvements and respective measures to advance the ability to benefit from specialisation and collaboration along the value chain. The presented model is developed based on a classification of related state-of-the-art in maturity models to assess individual factors of networkability which are integrated to form an overall framework comprising six components and respective factors to be assessed. As networkability maturity addresses the interrelation of strategy, organisational design and information systems design, the paper adheres to requirements for effective design science research applied to the process of construction of a networkability maturity model applicable for health care providers. It therefore concludes with a case-based evaluation according to the design research literature and identification of further research.
\end{abstract}

Keywords Networkability · Maturity model · Health care · Enterprise interoperability

\footnotetext{
R. Fitterer $(\bowtie) \cdot$ P. Rohner

Institute of Information Management, University of St. Gallen,

Mueller-Friedberg-Strasse 8, 9000 St. Gallen, Switzerland

e-mail: rene.fitterer@unisg.ch

P. Rohner

e-mail: peter.rohner@unisg.ch
} 


\section{Introduction}

Continuously rising costs and increasingly restrained budgets for health care put pressure on the public health system (Slembeck 2006; Weisbrod 1991). A comparable low division of labour and integration of processes along crossorganisational patient therapy provides large potential for improvements in efficiency and effectiveness. The current state of health care employs the services of doctors from different fields of medicine such as surgery or internal medicine to be combined with those of nursing care, which also offers highly specialised services such as intensive care, as well as with cross-disciplinary medical services such as laboratory or radiology across a number of organisations. The staff that is directly involved in patient treatment or in cross-disciplinary medical services are assisted and provided with resources by supporting organisations, e.g. logistics or infrastructure.

Faced with challenges in operational efficiency, costs or quality in the provision of medical and care services (Farsi and Filippini 2006), hospitals-the largest and most complex entities of health care providing organisations-have increasingly recruited personnel with a business background for management roles (Anderson and McDaniel 2000). However in contrast to most other industries, when it comes to formulating objectives, defining services or designing processes which cut across professional groups, there is a lack of common perspectives (Braun von Reinersdorff 2007), which can be attributed to differences in education, incentives, value systems, etc. (Glouberman and Mintzberg 2001).

These features give rise to operational problems of cohesion and require health care providing organisations to deal with diverse and heterogeneous internal and external stakeholders that need to be integrated-characteristics and challenges typically attributed to business networks. While all parties are interested in advancing efficiency and effectiveness of the overall network, each party seeks to ensure own benefits and may also have different perception of how to best develop the entire network. In order to advance health care value chains, which are producing high quality and efficient services for the healing and relief of acute illnesses, for preventive healthcare and for the permanent care of the chronically ill, networkability, i.e. "both the internal and external capability of organisations to collaborate with each other at the level of both business processes and underlying ICT infrastructure' (Wigand et al. 1997) is a key determinant. On a strategic, organisational and technical level, it is a key requisite to benefit from specialisation and collaboration with business partners without causing major costs for each partnership initiated.

Based on a model of networkability influencing factors for the health care sector, this paper presents an approach to assess the maturity of an organisation's networkability, which forms the foundation for improving the capacity to efficiently engage in business relationships, an essential requirement to benefit from collaboration across the health care value chain. As networkability maturity addresses the interrelation of strategy, organisational design and information systems management, the paper adheres to the design science guidelines outlined in 
(Hevner et al. 2004; Venable 2006) applied to the process of construction of a networkability maturity model to assess health care providers.

In the following section a definition of networkability in general and the health care sector in particular is provided on which the work in this paper is built upon. Based on this definition, existing research that has identified factors influencing networkability on strategic, organisational and system level is presented and the need for an assessment framework is discussed. For enabling assessment of the current networkability performance of an organisation, a model is required that identifies interdependency of these factors and their order of priority in advancing networkability.

Building on the concept of maturity as an assessment criterion, in the following two sections a review and classification of related state-of-the-art in maturity models to assess individual factors of networkability or groups of them is carried out. As a result, adequate groups of maturity models are identified that form the foundation for designing a networkability maturity model based on accepted concepts for performance assessment of individual and groups of factors of networkability.

Subsequently the requirements for construction of such a maturity model are presented and consolidated into a meta model of networkability influencing factors. Based on the classification of maturity frameworks, in the remainder of this work a networkability maturity model is constructed that integrates the model of factors of networkability with relevant existing maturity frameworks.

Finally, this work is then set into the context of relevant 'requirements for effective design science research' (Hevner et al. 2004) and evaluated using an instantiation of the model, which has been applied in a pilot group. The paper concludes with guidance on future research for designing and further evaluating the presented artefact (Simon 1969, p. 114) as well as guidance on potential purposes for the application of the model.

\section{Defining networkability and networkability maturity}

In the context of division of labour and specialisation of partners in a value chain, networkability is a key requirement for organisations in the information age. Networkability describes the ability to cooperate internally and externally (Wigand et al. 1997, p. 11) and constitutes an organisation's capacity to efficiently and rapidly engage in business relationships with business partners (Österle et al. 2001, p. 5). It is not limited to system-to-system interoperability on a software application level as is the focus of (Frießem et al. 2005; Lenz et al. 2005; Schwarze et al. 2005). Instead, the notion of networkability, as used in this paper, covers corporate interoperability from a strategic, organisational and system point of view according to the layers of the Business Engineering Framework described in (Österle and Winter 2003). This concept of networkability is consistent with and supported by research in the field of enterprise interoperability, cp. (Chen 2006) - a research initiative funded by the European Commission under the INTEROP Network of Excellence-as well as the work of the technical committee 'Enterprise Integration 


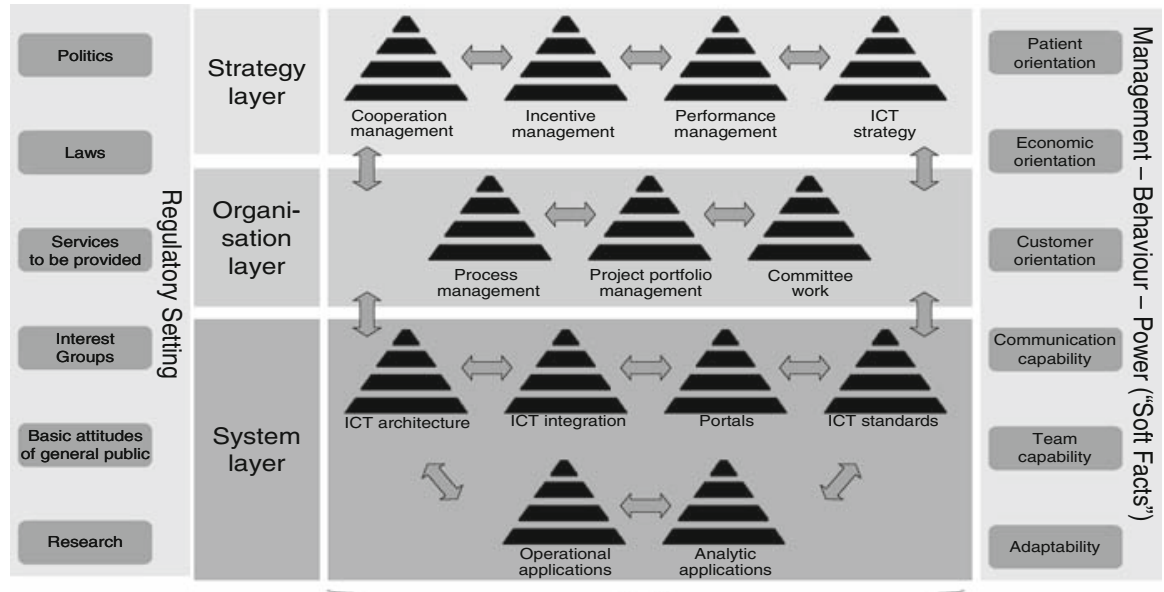

Networking Design Objects ("Hard Facts”)

Fig. 1 Model of networkability influencing factors in the health care sector (Mettler et al. 2007)

and Networking' of the International Federation of Automatic Control. ${ }^{1}$ The value of networkability lies in its contribution to enabling health care providing organizations 'to link up with other players [...] for the joint provisioning of patient-centred and cost-efficient health services' (Mettler and Rohner 2009a) and is grounded on the assumption that 'network members can achieve goals that would not be possible or would have a higher cost if attempted by them individually [...][a factor particularly relevant] for none-profit/social-oriented contexts' (CamarinhaMatos and Afsarmanesh 2005).

Addressing networkability of health care providing organizations Gericke et al. (2006) analysed 'design objects of networkability' (Alt et al. 2000, p. 406). Gericke et al. (2006) thereby focused on the operational efficiency of administrative processes of health care providers as a means to support medical excellence. This focus on operational efficiency and use of information technology (IT) as an enabler of more efficient and effective health care value chains rather than a driver of change in medical treatment processes is also applied in this work.

The constructs identified by Gericke et al. (2006), e.g. 'process documentation', 'electronic processes', were then consolidated into clusters, e.g. 'process management'. Initial relations between clusters have been established to depict interdependencies and build into a model of networkability influencing factors (cp. Fig. 1). The model has been evaluated and checked for comprehensibility in a survey which involved different actors from the health care sector of Switzerland (Mettler et al. 2007).

Gericke et al. (2006) already pointed out the need for 'development and maturity stages' to be defined in order to enable assessment of the current networkability of

\footnotetext{
1 We distinguish between enterprise interoperability in a holistic sense, for the remainder of this work referred to as networkability, and technical (e.g. IT systems to systems) interoperability referred to as interoperability.
} 
an organisation and to provide recommended actions for advancing it. While the clusters have been empirically evaluated for their influence on the networkability of a single organisation and the health care sector as a whole, no statement could be made on their interdependency or order of priority in advancing networkability. Hence, there is a need to identify these relations and develop a 'roadmap for increasing the networkability of the health care sector' (Mettler et al. 2007). The maturity model presented in this paper aims to provide such a roadmap by addressing networkability from a process perspective (Paulk et al. 1993a). In order to explore the potential of such a networkability maturity model, we have carried out an exploratory analysis. Expert knowledge was required to gain the necessary information on the applicability and utility of a networkability maturity model in health care. Therefore, the focus of the study was on the key actors or influential persons who can drive implementation of measures to enhance networkability, i.e. primarily management staff of the business/medical units and management staff of the IT departments within health care providing organisations. ${ }^{2}$ Out of 41 distributed questionnaires, we received a total return of 28 , which results in a response rate of $68.3 \%$. From this sample, 24 were completed by hospital staff and four questionnaires by governmental health care deputies. $50 \%$ of the respondents described themselves as working in a management position. The remaining respondents were IT or business specialists $(39,3 \%)$, or people working at supporting units, e.g. logistics $(10,7 \%)$. In order to ensure comprehensibility, the respondents were supported by a research assistant in case of an unclear question item. However, external influence over one particular respondent was reduced by answering them simultaneously and conjointly.

$37 \%$ of the respondents rated their level of experience with maturity models to be above entry level ( 1 respondent at expert level, 8 respondents at an advanced level), $53 \%$ were at entry level, and $10 \%$ had no experience with maturity models yet. Those respondents who already had applied maturity models in the domain of networkability most commonly applied them to assess aspects of IT management and IT processes, process management and (project-)portfolio management.

Figure 2 illustrates the survey results on the potential purpose and domain (medical/administrative) of networkability maturity model application. From the figure, it is possible to determine that assessment of the current state of an organisation and advancement of this state are considered the two most relevant purposes, which supports the potential utility of the model presented in this work. Internal benchmarking, i.e. comparison between individual units of an organisation is considered to be least important. Hence, holistic assessments of the networkability maturity of an organisation are considered more important than identifying individual underperforming units. From the survey, it can also be concluded that addressing the

\footnotetext{
2 A questionnaire was used to collect the data. The responses were scored on a five-point Liker scale. For example, one of the items asked, 'Networkability maturity models are suitable for the assessment of the current state of an organization', possible responses ranged from 5 (strongly agree) to 3 (neither agree nor disagree) to 1 (strongly disagree). The data collection of this study was carried out in January 2009 as part of an expert workshop held in Switzerland. For missing information, we applied the strategy of pairwise deletion in order to preserve information. A potential bias to correlations or covariances resulting from pairwise deletion was of no concern for the types of analyses applied (Tsikriktsis 2005).
} 


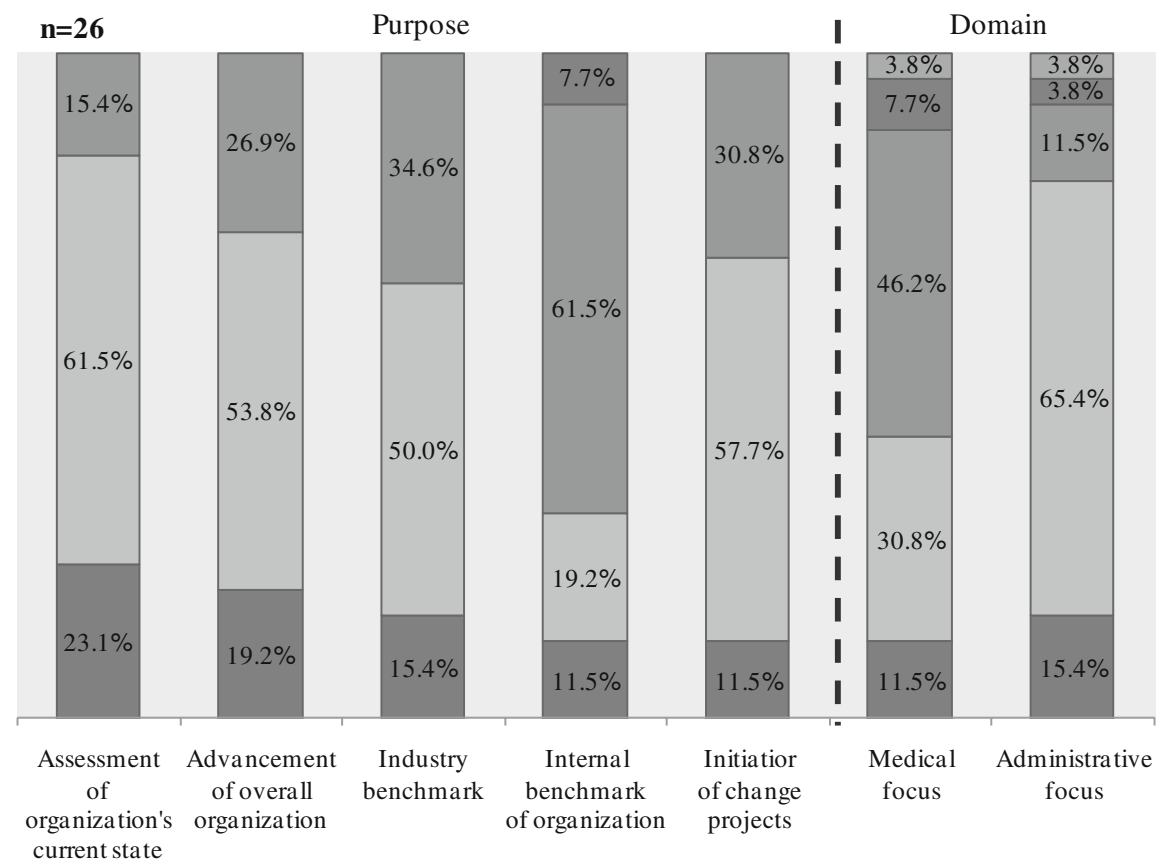

$\square$ Strongly agree $\quad \square$ Agree

$\square$ Neither agree or disagree

$\square$ Disagree

$\square$ Strongly disagree

Fig. 2 Areas of application of networkability maturity models

administrative domain of health care providing organisations is considered more relevant in terms of advancing networkability. This supports the findings of Gericke et al. (2006) who proposed to improve the operational efficiency of administrative processes of health care providers as a means to support medical excellence.

While the presented survey is limited to Swiss health care providing organisations and the sample can by no means be considered representative for the overall population of health care providing organisations, it indicates that maturity models can be considered a means to holistically assess and improve networkability capabilities.

The subsequent section investigates existing and accepted capability and maturity frameworks that target individual or groups of design objects of networkability to assess their applicability for identifying the interdependencies between the clusters. Based on this analysis, a networkability maturity model is designed with a specific focus on health care providers and addressing the 'hard facts' of the networkability influencing factors as these can most directly be influenced towards creating positive impact on the health care value chain.

\section{Maturity models and classification criteria for applicability to networkability}

Maturity assessment approaches mainly originate from the field of quality management. Maturity, 'the state of being complete, perfect or ready' (Simpson 
and Weiner 1989), as an assessment criterion for quality management has been first introduced in Crosby's quality management maturity grid (CQMM) (Crosby 1979). Crosby (1979) defined five evolutionary stages of how an organisation adopts quality practices which draw on similar concepts as those of (Gibson and Nolan 1974), who observed that an organisation traverses various stages in adopting technology. These formed the foundation of one of the most widely accepted process maturity frameworks: Capability Maturity Model for Software (SW-CMM) (Paulk et al. 1993a, b) and its successor, the Capability Maturity Model Integration for Development (CMMI) (CMMI Product Team 2006). CMMI defines five maturity levels to assess an organisation's process improvement achievements. As CMMI targets primarily software development and acquisition processes, the concrete model cannot directly be applied for designing a networkability maturity model. However, the concepts of CMMI are reused in various state-of-the-art maturity models addressing non software engineering related topics (Curtis et al. 2001; Kwak and Ibbs 2002) which are applicable for previously described clusters of networkability.

In order to make best use of the knowledge base and to identify categories of maturity models that address individual or groups of networkability maturity influencing factors, we applied a framework of criteria to classify existing maturity models based on the work of (Fettke et al. 2005). The original framework for classification of reference models has been extended to include criteria that assess the appropriateness of state-of-the-art for usage in the design of a networkability maturity model. The applied classification criteria are:

- General Characterisation: To achieve desired rigour in design science, a prerequisite is foundation on a high quality knowledge base (Hevner et al. 2004). The framework therefore classifies maturity models according to origin (academia/practice), scope and diffusion in the intended problem space.

- Application: The method for applying the model, e.g. CMMI-like, hybrids or Likert-like questionnaires (Fraser et al. 2002), and maturity levels.

- Applicability: In this group of criteria, relation of the subject matter to cluster or design objects of networkability are described as well as industry applicability to the health care sector.

\section{Classification of existing maturity models}

In total 24 maturity models were assessed for their applicability for the composition of a networkability maturity model. Based on applicability criteria and origin, a preselection of maturity models has been carried out. This section presents categories of maturity models based on their scopes as this was considered most relevant for the desired identification of interdependencies between the clusters presented by Mettler et al. (2007). An overview of maturity models categorised by their scopes is shown in Table 1, which also identifies their degree of applicability to previously described networkability influencing factors using Harvey Balls. 


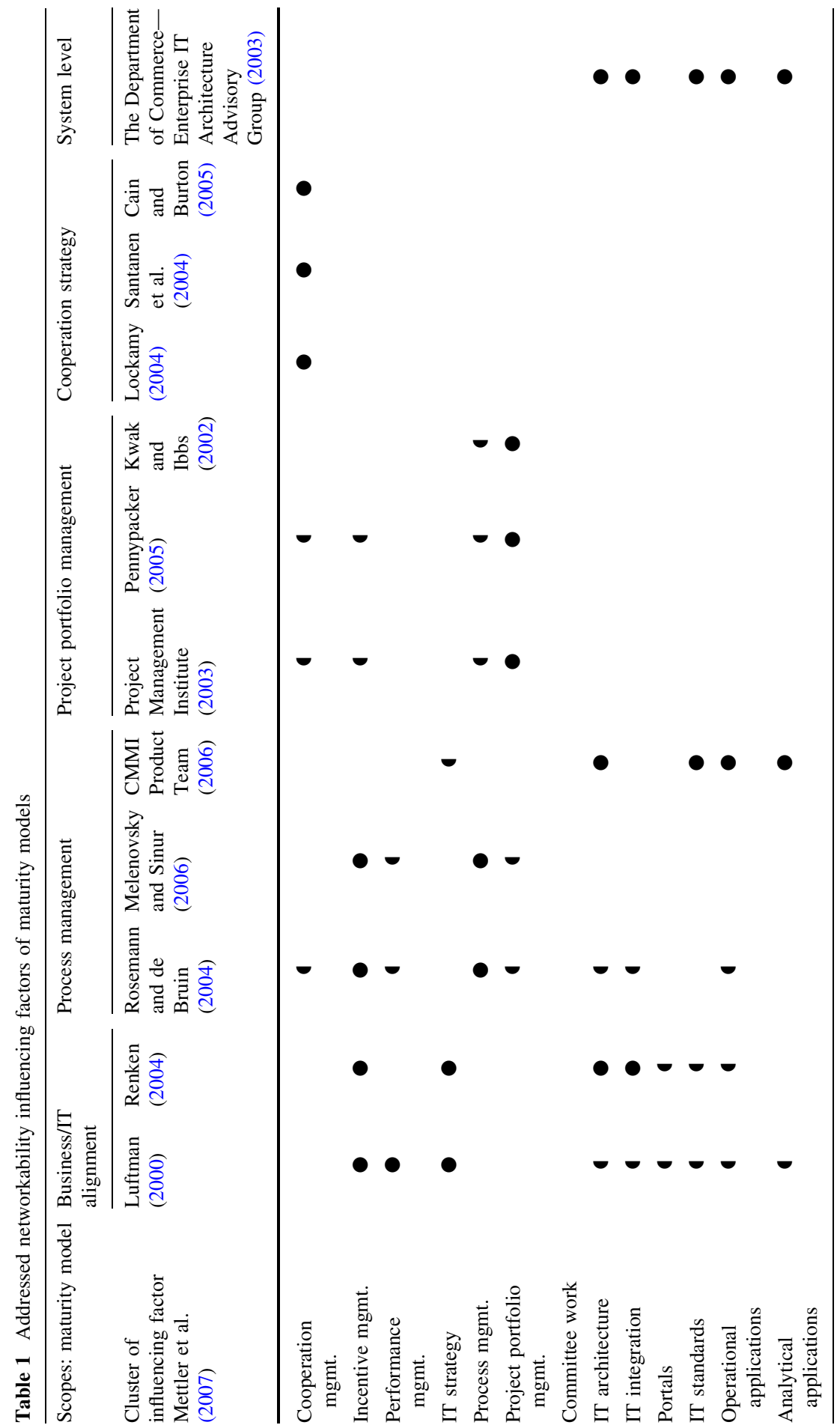




\subsection{Business-IT Alignment}

The first category contains a group of models concerned with strategy alignment, as regards to how $\mathrm{IT}^{3}$ is aligned with business strategies of an organisation and vice versa. The core maturity construct of this group, alignment, is based on the principle of a close integration of IT strategy with the organisation's business strategy as supported by Österle and Winter (2003). The Business-IT Alignment Maturity (Luftman 2000) is based on twelve components of alignment which are split into four groups: 'business strategy', 'organisation infrastructure and processes', 'IT strategy' and 'IT infrastructure and processes' (Luftman 1996). These groups closely match and relate parts of the networkability influencing factors both horizontal within the 'strategy' layer as well as vertically across with regards to elements of IT management. Similarly, the IS/ICT Management Capability Maturity Framework (Renken 2004) assesses the maturity of alignment of IT management on a strategic, operational and system level with respect to internal alignment of IT management and with surrounding business factors such as business strategy and IT users. Both previously described maturity models for strategy alignment use a CMM-like concept of evolutionary levels. Interfacing with the strategy layer and assessing the maturity of 'strategy execution' (Henderson and Venkatraman 1993) a set of maturity model categories exist that deal with the capabilities of implementation of defined strategies on the organisational level which are described in the following.

\subsection{Process management}

With regards to the cluster 'process management', the most comprehensive maturity framework assesses business process management maturity (BPMM) by the factors 'strategic alignment', 'culture', 'people', 'governance', 'methods' and 'IT/IS' (Rosemann and de Bruin 2004). BPMM addresses the management maturity of business processes and not the maturity of the processes themselves. Hence, it assesses the 'coverage and proficiency' (Rosemann and de Bruin 2004) of business process management (BPM), a more relevant determinant of networkability. There is limited additional coverage in research on maturity of process management as a whole. In a recent study, Melenovsky and Sinur (2006) used the previously stated factors defined by Rosemann and de Bruin (2004) to identify six phases for BPM adoption.

\subsection{Project portfolio management}

Project portfolio management is defined as 'the application of knowledge, skills, tools, and techniques to organisational and project activities to achieve the aims of an organisation through projects' (Fahrenkrog et al. 2003) and synonymously referred to as organisational project management (OPM) by the Project

\footnotetext{
${ }^{3}$ The term IT is often also synonymously referred to by Information and Communication Technology (ICT).
} 
Management Institute (PMI). The Organisational Project Management Maturity Model (OPM3) (Fahrenkrog et al. 2003; Project Management Institute 2003) defines three factors to be assessed, 'portfolio management', 'program management' and 'project management', which are further divided into five stages from initiating processes to closing processes. The assessment is based on best practices and related capabilities defined for the different levels of maturity of the factors. OPM3 uses a four-point scale of maturity that slightly differs from the standard CMMI levels. The Project Portfolio Management Maturity Model (Pennypacker 2005; Project Management Institute 2003) addresses the same subject-matter using a set of six factors and maturity levels based on CMMI. A framework defined by Kwak and Ibbs (2002) assesses Project Management Process Maturity from a bottom-up perspective. Using the PMI process stages and a set of nine project management knowledge areas, this framework addresses the maturity of management of individual projects which on a higher level of maturity are supported by project portfolio management.

\subsection{Cooperation strategy}

Cooperation strategy, an organisation's orientation towards strategically setting up cooperation with business partners, is addressed by maturity models from a variety of fields, most prominently by supply chain management (SCM). Using a CMMbased approach, Lockamy (2004) defines a model for SCM maturity assessment from a management process perspective. While supply chains commonly refer to upstream and downstream cooperation, this model is also applicable for horizontal partnerships as it addresses an organisation's strategic management, preparedness and organisational orientation towards cooperation. Another aspect of cooperation strategy is collaboration management, i.e. the ability to design and deploy processes for recurring collaborations with the objective of creating sustained collaboration practices (de Vreede and Briggs 2005). It is assessed by the Collaboration Engineering Maturity Model (Santanen et al. 2004) which uses a four-point scale of maturity and is based on the special concept of thinkLets which can be considered as a way of standardising collaboration facilitators (Briggs et al. 2003). A more generic approach to assessment of collaboration maturity is proposed by (Cain and Burton 2005). Using a five-point scale, it measures the level of strategic management, coverage within and across organisations as well as the type of support provided for collaboration.

\subsection{System level}

Networkability is dependent on an organisation's ability to cooperate and efficiently engage in business relationships. This has implications on the relevant scope of maturity to be addressed on a technical level. Focus is to be directed on architecture, integration and observation of standards as an enabler of networkability and related business and IT strategy (van der Raadt et al. 2005) as a contribution to the networkability of the organisation on strategic and operational level. While architecture maturity in itself (The Department of Commerce-Enterprise IT 
Architecture Advisory Group 2003) is a determinant of networkability, it needs to be assessed in the context of previously described models addressing IT strategy alignment and IT management.

\section{Construction of the networkability maturity model}

The classification of existing maturity models described in the previous section is the basis for the selection of existing frameworks to design the networkability maturity model. In particular relevant for the applicability to create an overall maturity model are the consistency and compatibility of maturity levels and the ability to measure the networkability influencing factors. With regards to the maturity levels to be assigned, the classification (cp. section 'Classification of Existing Maturity Models') showed us that all clusters can be assessed by a CMMlike five point scale. While the concrete meaning of these levels varies depending on the subject assessed, a consistent scale of maturity facilitates in deriving the overall networkability maturity. Hence, compatibility with a CMM-like set of maturity levels is considered an important selection criterion.

To clarify the terminology used when designing the networkability maturity model, a meta model is presented in Fig. 3. Component, factor and networkabilitymaturity are terms introduced to the problem scope in this paper, the terms design object of networkability and clusters are reused from (Gericke et al. 2006; Mettler et al. 2007).

The groups of maturity models described in the previous section show that existing models address a variety of topics at different levels of abstraction and that they are not disjoint concerning the addressed clusters or design objects of networkability. When designing the components of the networkability maturity model, these overlaps and inconsistencies between selected existing maturity models need to be removed to avoid redundancies and enable coherent assessment of individual components. This implies the potential need to reassign factors combined in single state-of-the-art models into different components of the

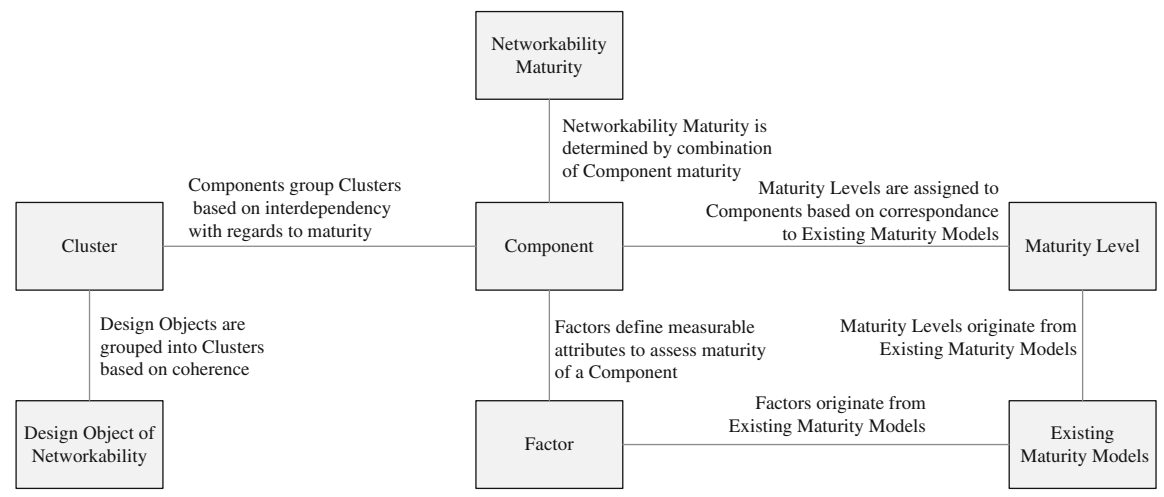

Fig. 3 Meta model of networkability influencing factors 
designed maturity model. To maintain correctness and consistency of the existing frameworks if their factors are split across different components, resulting interdependencies need to be identified between the respective components. In cases where factors of an existing maturity model are a redundant part of more than one component and cannot be extracted into a separate component, they either need to be assessed by unified measures or addressed from different perspectives that allow for different assessment criteria.

Based on the classification of existing maturity models and the principles for the design of the networkability maturity model stated in this section, the components of the networkability maturity model are subsequently described.

\section{Components of the networkability maturity model}

The framework to assess the networkability of health care providers' administrative processes is designed to consist of six components. Two components span horizontally across the strategy and system layers, four components addressing strategy execution span vertically across the Business Engineering layers. The components and their relation to an adapted version of the clusters defined by Mettler et al. (2007) are shown in Fig. 4.

Based on (Henderson and Venkatraman 1993) and adapted to networkability, the component strategic alignment assesses consistency of the subsequently described strategy execution components of networkability. It addresses the internal alignment of IT strategy and business strategy (execution and change) and the external alignment towards cooperation and networkability.

The four components concerned with strategy execution are: IT management, process management, organisational project management and cooperation

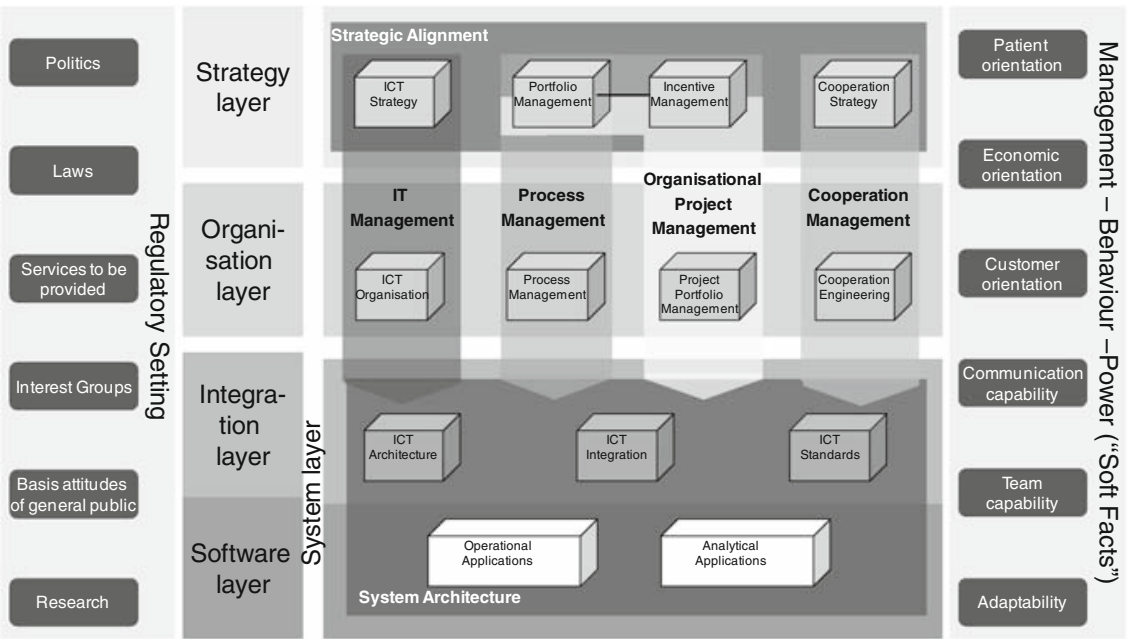

Fig. 4 Networkability maturity model for health care providers 
management. These components assess how IT, portfolio, incentive and cooperation strategies are tailored towards networkability as well as how they are institutionalised and executed on the organisation level.

The design of these four components is backed by the enterprise framework and its core categories of organisation management defined in the New St. Gallen management model (Rüegg-Stürm 2005) when examined from a networkability perspective. The core areas of this model are 'processes', 'configuration forces', 'modes of development' as well as surrounding aspects. The category 'configuration forces' is addressed by two elements in the model of networkability influencing factors being 'regulatory setting' and 'management-behaviour-power' which are not considered for networkability maturity in this article. The second category 'processes', relating to all aspects of activities along the value chain, is assessed by the component process management. 'Modes of development', relating to patterns of organisational change processes such as renewal or optimisation, is addressed by the category organisational project management. The relevant surrounding elements for networkability, being business partners such as suppliers or health care organisations, are addressed by the component cooperation management. These three aspects are extended by one that is not explicitly represented in the New St. Gallen management model but core to Business Engineering and networkability: the support and enablement through IT assessed by the component IT management.

The assessment of IT aspects is externalised from the strategy execution components into the component system architecture. The reason is that an individual examination is not suitable for assessment of the overall networkability. Analogue to strategy alignment, the component system architecture addresses the ability of IT to enable and drive networkability advancement on the organisation and strategy level in a consistent manner as postulated by the Business Engineering concept of IT-business alignment (Teubner 2006).

The overall focus of the networkability maturity thereby lies on the internal aspects of networkability, i.e. components and factors that need to be addressed to advance capabilities to participate in collaborative networks (cp. section 'Defining Networkability and Networkability Maturity'). There is an extensive body of knowledge on how to promote and manage collaborative networks from a crossorganisation point of view through creation of different kinds of institutions (e.g. virtual enterprises/organisations or professional virtual communities) (CamarinhaMatos and Afsarmanesh 2005) by establishing 'virtual organizations breeding environments' (Afsarmanesh and Camarinha-Matos 2005), which we recommend as further reading but have excluded from the scope of the internal view on networkability.

The described components form the basis for defining the concrete meaning of the maturity levels for each component and the assignment factors to be assessed. In addition to proficiency, the level of coverage (Rosemann and de Bruin 2004) needs to be addressed to assess networkability in detail. This refers to the level at which strategies are defined, quota of departments involved on the organisation layer and the share of users accessing and benefiting from provided system architecture. In the subsequent sections each of the components is described in detail, an overview of 
Table 2 Networkability maturity components and related factors

\begin{tabular}{ll}
\hline Component & Factors \\
\hline Strategic alignment & Communication, partnership, strategy governance \\
$\begin{array}{l}\text { IT management } \\
\text { Process management }\end{array}$ & $\begin{array}{c}\text { BP governance, IT organisation, IT performance, IT scope, IT strategy } \\
\text { governance, people }\end{array}$ \\
$\begin{array}{l}\text { Organisational project } \\
\text { management }\end{array}$ & OPM governance, OPM assessment, OPM communication, people \\
$\begin{array}{l}\text { Cooperation management } \\
\text { Collaboration engineering, committee work, cooperation strategy, partner } \\
\text { Systems architecture }\end{array}$ & selection \\
\hline
\end{tabular}

the networkability maturity assessment factors for each component is provided in Table 2.

\subsection{Component strategic alignment}

Strategic alignment is considered a core component as it addresses the synchronisation and governance of the four pillars of strategy execution. Its determining factors are derived from (Luftman 2000). Alignment is measured by the factors communication and partnership, referring to a mutual understanding and knowledge about strategic directions, knowledge exchange and shared goals. This strongly relates to maturity of the factor strategy governance, which is addressing policies and activities related to strategic planning, investment planning, reporting structures on management level and establishment of steering committees. The remaining factors defined by Luftman (2000), 'skills', 'competency/value measurement' and 'scope and architecture', are addressed within the strategy execution components and therefore not part of this component.

\subsection{Component IT management}

The component IT management interfaces with strategic alignment through its factor IT strategy. Addressing maturity of IT management on strategy and organisation layer, its assessment factors are extracted from (Renken 2004) and the remainder of factors of (Luftman 2000). The factor IT strategy addresses managerial aspects such as strategic and investment planning of IT as well as managerial paradigms of IT, e.g. moving from a technology-centred to a more people-centred, business-oriented strategy. The factor IT scope addresses the breadth of IT management both in its horizontal and vertical expansion of business operations addressed. The factor IT organisation addresses its structure, representation and skills. The maturity of performance and quality metrics of provided services is assessed by the factor IT performance, addressing how well these metrics are established and executed, and also how well they are governed which is assessed by the factor IT governance, which addresses not only technical 
aspects but also IS-related issues such as compliance with standards/taxonomies in policies and procedures. This component therefore addresses an IT organisation's development from being a technology centred support organisation of business, to a driver and enabler of innovation with a clear profile and quality of services provided.

\subsection{Component process management}

The component process management reuses the concepts presented in (Rosemann and de Bruin 2004) directed towards assessment of the maturity of management of processes. Networkability strongly depends on how processes are managed across departmental and organisational boundaries. Process management is measured by the factors BPM alignment, BPM methods, BPM governance and people. BPM alignment refers to the level of process management and process implementation being aligned with strategic and operational goals, meaning how well business strategy is institutionalised in processes. The factor BPM methods addresses the process management methodology and techniques with which an organisation is equipped and their compatibility with internal and external references. Available methods determine networkability maturity as they influence an organisations capability of managing interdependent tasks distributed across locations and organisations. The factor BPM governance addresses how well advancements towards a process-centric organisation are guided and supported by means of accountability, formalisation in decision-making and support of improvement in processes. The factor people address how well process orientation is established in the organisation's personnel.

\subsection{Component organisational project management}

The component organisational project management (OPM) addresses organisational activities to achieve its aims through projects as presented in (Fahrenkrog et al. 2003; Pennypacker 2005). Concerning networkability, it addresses how well OPM is enabled to implement the business strategy e.g. in projects to change, optimise or establish internal or cross-organisational processes or business partnerships. The factor OPM governance addresses how well metrics and governance processes are established to guide and assess the implementation of strategic project portfolio decisions on organisation level. The factor OPM assessment refers to project opportunity assessment, prioritisation and selection, i.e. the ability to assess project risks and opportunities based on past experience and assessment metrics. The factor OPM communication is an enabler of the previous factor as it determines how effective communication structures as well as knowledge collection and management are established. The capability to efficiently assign and manage skills and resource of available personnel is addressed by the factor people. The overall maturity of the component OPM addresses very directly an organisation's efficiency in selecting and executing projects that foster networkability but also its ability to standardise projects and benefit from past experience. 


\subsection{Component cooperation management}

Assessing an organisation's orientation towards cooperation with business partners on a strategic and organisation level, the factors of this component originate from collaboration maturity (Cain and Burton 2005; Santanen et al. 2004) and supply chain management maturity (Lockamy 2004; Cain and Burton 2005) models. The factor cooperation strategy relates to the extent that cooperation is considered a strategic tool to foster efficiency and effectiveness. Collaboration engineering is a factor that measures how well an organisation is able to support division of labour through adequate support of collaboration processes and interaction patterns. To successfully engage in business networks, particularly with new partners, the factor partner selection addresses how well processes are established to identify risks and required counter measures of a certain business partnership. A soft factor of cooperation management, yet relevant for establishing business relationships and driving cooperation, is committee work. This factor addresses how well an organisation is connected in committees and bodies relevant to identify cooperation opportunities.

\subsection{Component system architecture}

The component system architecture, which addresses the contribution of system interoperability to networkability, measures an organisation's ability to enable and drive strategic and organisational initiatives oriented towards networkability. In line with the IT-business alignment considerations presented before, IT may never be assessed by itself but always in the context of its alignment with business strategy and operation. The maturity of system architecture is based on factors contained in (Luftman 2000; van der Raadt et al. 2005) and (The Department of CommerceEnterprise IT Architecture Advisory Group 2003). It is assessed by the factors IT architecture and IT integration with relation to the capability to drive business networkability, by enabling information flow and interaction in processes and projects, e.g. using semantic and syntactic standards. The factor IT applications addresses the scope of applications provided, relating to the extent that line-ofbusiness applications, transactional applications or analytical applications are included in the system architecture.

\subsection{Maturity levels}

As pointed out in the section 'Construction of the networkability maturity model', addressing networkability from a process perspective all six components of the maturity model can be assessed by a five-point CMMI-like set of maturity levels. While the CMMI maturity levels are defined in a context different to networkability, their wide adoption also in other fields is reason for applying them also for the proposed networkability maturity model. This decision is supported by experience from Rosemann and de Bruin (2004) who initially developed their own set of maturity levels for the BPMM but after a review of the initial model draft changed to the CMMI levels. The maturity model presented in this work therefore uses the 
Table 3 Example of maturity level definition for the factor IT governance of the component IT management

\begin{tabular}{ll}
\hline Maturity Level & Definition for the factor IT governance \\
\hline Initial & $\begin{array}{r}\text { IT strategy defined, no measures and activity derived to assess implementation on } \\
\text { organisation/strategy execution level } \\
\text { Measures defined, no target system (incl. metrics) defined in IT strategy }\end{array}$ \\
Managed & Measures and target system defined but missing interconnection between the two \\
Defined & $\begin{array}{l}\text { Integrated assessment of IT measures and target system using e.g. balanced } \\
\text { Quantitatively } \\
\text { managed }\end{array}$ \\
Optimising & Continuous feedback loop between strategy execution and IT strategy. Measures and \\
& target system continuously optimized and adapted
\end{tabular}

five stages of CMMI being 'Initial', 'Managed', 'Defined', 'Quantitatively Managed' and 'Optimising' (CMMI Product Team 2006).

For the generic maturity levels, a detailed definition is required of their meaning for each component of the networkability maturity model as it varies depending on the component and respective factors being considered. Table 3 presents such a definition for the factor IT governance that provides concrete denotation of the five levels in the context of the component IT management.

The described level definitions are an excerpt from an instantiation of a networkability maturity which has been developed by the authors together with a health care consultancy. The results of its application in a pilot group are described in the subsequent section. Addressing the quality of the constructed artefact described in this section with regards to its rigour and relevance, the subsequent section thereby first discusses relevant design research guidelines set up to ensure quality of such a research process and then applies them to the work presented in this paper.

\section{Evaluation}

The work presented in this paper is based on the design science paradigm postulated in (March and Smith 1995; Simon 1969). According to March and Smith (1995), design research is defined to 'produce and apply knowledge of tasks in order to create effective artefacts' that 'serve human purposes' which can be in the form of a construct, model, method or instantiation. Design research therefore is a problemsolving paradigm which aims to create new and innovate artefacts that address relevant problems (Hevner et al. 2004) and it is considered a valuable approach in the health care domain (Owen 1998).

Through its maturity levels and assessment approach, the developed artefact represents a framework containing goals and practices how to advance networkability maturity, hence a design method according to the definition (Hevner et al. 2004; March and Smith 1995). Based on the design science paradigm, procedure models describing the design research process were developed (Hevner et al. 2004; 
Peffers et al. 2006) that address and characterise main phases of design research. As a core phase, evaluation determines an artefact's rigour and relevance.

Hevner et al. (2004) require that relevance, i.e. 'utility, quality and efficacy [...] must be [...] demonstrated via well-executed evaluation methods' and respective metrics. Evaluation of relevance hence primarily refers to determining the effectiveness and efficiency in solving (or contributing to solve) the addressed problem. Based on the list of evaluation methods provided in (Fettke and Loos 2003; Hevner et al. 2004) and the experience from Rosemann and de Bruin et al. (2005) and Tapia et al. (2007), application of the maturity model within a pilot group from the target audience is considered a preferable evaluation instrument. It allows validation of artefacts in their early stage of development and in their reallife-context. It is thereby necessary to deploy the artefact to entities not involved in the design process of the artefact in order to ensure generalizability of the results.

We developed an instantiation of the maturity model to assess the organizations current state of networkability with a focus on the aspect of eHealth adoption within hospitals. This instantiation has been applied in a pilot group of five public Swiss hospitals employing between 300-3,000 employees (average 1,340, median 1,200) and handling 30,000-300,000 inpatient days (average 142,000; median 130,000). In each hospital, we interviewed the Chief Information Officers/Heads of IT departments as well as approximately 20 people from the business/medical departments (primarily management staff).

Advancing adoption of eHealth is in the current focus of Swiss hospitals and the Swiss Federal Office of Public Health, which promotes eHealth through its 'Strategy eHealth Switzerland' (Bundesamt für Gesundheit 2007). In general eHealth relates to a 'model of health care where stakeholders collaborate utilising ICTs including Internet technologies to manage health, arrange, deliver, and account for care, and manage the health care system' (Ontario Hospital eHealth Council 2001). The current state of eHealth in Switzerland focuses however on 'health care's component of business over the Internet' (Blutt 2001) hence addresses administrative and back-end issues of ICT-based collaboration of health care providing organizations rather than directly impacting the processes and activities of care service delivery, which matches the understanding of networkability as proposed in this article.

Method artefacts such as the networkability maturity model described in this work need to be designed rather generic and have to be extended resp. configured to be applicable to a specific problem using a set of method fragments (Brinkkemper 1996) which are represented by the components of the maturity model. Based on a model of the integration of business and IT, which in the current state of eHealth adoption is achieved as shown by the curved arrow in Fig. 5, we have excluded the factors process management and cooperation management for the pilot group as eHealth activities in Switzerland currently do not directly impact internal and crossorganizational processes of health care providing organizations. The remaining four components and respective factors have been assessed by a set of 47 variables.

Table 4 shows the results of the application in the pilot group. We have not assessed the factor IT scope as for this evaluation it was preset to the aspect of eHealth. The assessment showed that hospitals 1 and 4 have the highest 
Fig. 5 Areas of business and IT integration based on (Aier and Winter 2009; Henderson and Venkatraman 1993)

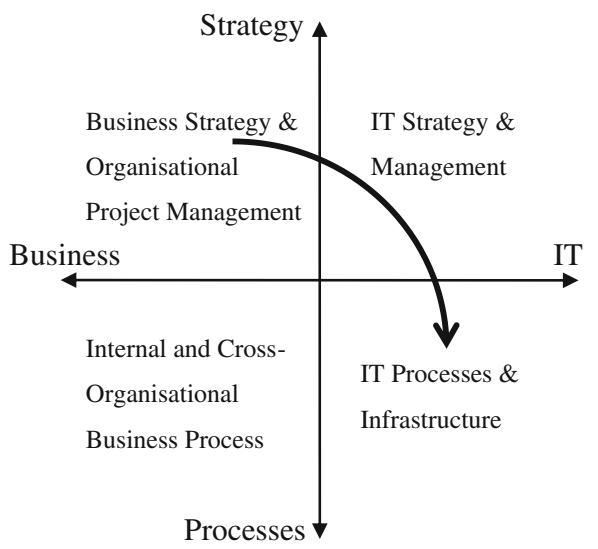

Table 4 Networkability maturity assessment results of the pilot group

\begin{tabular}{|c|c|c|c|c|c|c|}
\hline Component & Factor & $\begin{array}{l}\text { Hospital } \\
1\end{array}$ & $\begin{array}{l}\text { Hospital } \\
2\end{array}$ & $\begin{array}{l}\text { Hospital } \\
3\end{array}$ & $\begin{array}{l}\text { Hospital } \\
4\end{array}$ & $\begin{array}{l}\text { Hospital } \\
5\end{array}$ \\
\hline \multirow[t]{3}{*}{ Strategic alignment } & Communications & 1 & 2 & 3 & 3 & 0 \\
\hline & Partnership & 2 & 2 & 3 & 2 & 2 \\
\hline & $\begin{array}{l}\text { Strategy } \\
\text { governance }\end{array}$ & 2 & 0 & 1 & 3 & 0 \\
\hline \multirow[t]{5}{*}{ IT management } & IT gov & 2 & 1 & 3 & 3 & 2 \\
\hline & IT org & 3 & 1 & 2 & 2 & 1 \\
\hline & IT performance & 3 & 1 & 3 & 4 & 0 \\
\hline & IT scope & - & - & - & - & - \\
\hline & IT strategy & 3 & 0 & 0 & 4 & 0 \\
\hline \multirow{4}{*}{$\begin{array}{l}\text { Organisational project } \\
\text { mgmt. }\end{array}$} & OPM gov & 1 & 0 & 0 & 3 & 1 \\
\hline & OPM assessment & 4 & 0 & 0 & 2 & 0 \\
\hline & $\begin{array}{l}\text { OPM } \\
\text { communication }\end{array}$ & 4 & 0 & 0 & 3 & 1 \\
\hline & People & 4 & 2 & 3 & 3 & 1 \\
\hline \multirow[t]{4}{*}{ System Architecture } & IT arch & 3 & 1 & 2 & 3 & 3 \\
\hline & IT applications & 3 & 1 & 0 & 2 & 2 \\
\hline & IT integration & 2 & 1 & 0 & 1 & 1 \\
\hline & Total Average & 2.66 & 0.74 & 1.33 & 2.61 & 0.90 \\
\hline
\end{tabular}

Bold values identify the best result(s) for each factor

networkability maturity. While both hospitals realize approximately the same overall average score, the maturity in the individual factors shows that both reached this state through very different measures. Hospital 1 pursued a bottom up approach to realize networkability through a good level in the areas of operational quality (people, organisation, and project assessment), system architecture and IT management. In contrast, hospital 4 applied a top-down approach through concise strategy and governance measures. Hospital 3 can be considered a follower of the 
approach of hospital 4 by advancing networkability through strategic initiatives, which are however still to be implemented on a strategy execution level. Hospitals 2 and 5 where the two smallest hospitals participating in this pilot group and are at a low state of networkability maturity.

As a proof of the utility of the networkability maturity model, we were able to document a number of initiatives that were initiated after the respective assessments, which directly contribute to enhancing networkability in the context of eHealth and beyond. On the one hand, hospital 1 started an initiative to adapt the overall strategy to include aspects of e Health and IT management in order to improve strategic alignment. On the other hand, hospital 4 aims to improve IT integration through an enterprise application integration initiative and started to enhance organisational project management capabilities in order to improve its strategy execution capabilities. Both hospitals 1 and 4 started initiatives to establish dedicated boards/positions for IT-Business alignment to holistically close the respective identified gaps. Similar basic initiatives where initiated in the other hospitals focusing on strategy execution in hospitals 2 and 3 and on strategy alignment in hospital 5 to implement essential networkability capabilities necessary to participate in eHealth. The feedback from the participating hospitals as well as the initiatives that were started as results of the assessment support the utility of presented networkability maturity model despite the two factors cooperation management and process management not included in this evaluation.

Rigour in the context of maturity models relates to its design process (e.g. sufficient analysis of the knowledge base)—which has been extensively discussed in the previous sections - as well as the resulting artefact. Addressing rigour of the resulting artefact, we evaluated if the concepts/ontologies (primarily components and assessment factors) properly represent aspects 'that exist or are perceived to exist in reality' (Evermann 2005). Assessing how completely the addressed problem is represented in the maturity model we therefore evaluated how well the maturity model includes and is able to assess relevant aspects determining networkability of health care providers based on the design objects of networkability (Gericke et al. 2006). Table 5 shows the design objects of networkability that are relevant for hospitals and clinics when focusing on the administrative processes as elaborated together with focus groups (cp. section 'Defining networkability and networkability maturity'). Each of the objects has been assessed on how it is addressed by the six components. As shown in Table 5, each is assessed for its maturity by at least one component and one or more factors. The fact that some objects are addressed by more than one component originates from their granularity and the point that individual objects are addressed from different perspectives by the components. The presented mapping of design objects to the model of networkability maturity supports its ability to address the identified aspects, which determine an organization's ability to connect and cooperate with business partners.

While the presented evaluation addresses completeness of the model of networkability maturity, it does not include any pointers to the degree of reliability or validity of the designed artefact. Subsequent evaluation is required as part of future research to further confirm rigour and relevance of the designed maturity model. 
Table 5 Networkability maturity factors addressing design objects of networkability from the viewpoint of hospital/clinics

\begin{tabular}{|c|c|}
\hline $\begin{array}{l}\text { Networkability maturity } \\
\text { model components }\end{array}$ & Design objects of networkability for hospitals/clinics \\
\hline Strategic alignment & Business-IT alignment, integration of IT strategy into company strategy \\
\hline IT management & $\begin{array}{l}\text { Business-IT alignment, project and application portfolio, integration of } \\
\text { IT and organisation, service level agreements (SLAs) }\end{array}$ \\
\hline Process management & Process and quality assurance \\
\hline $\begin{array}{l}\text { Organisational project } \\
\text { management }\end{array}$ & $\underline{\text { Project and application portfolio }}$ \\
\hline Cooperation management & $\begin{array}{l}\text { Cooperation strategy, cooperation agreement, outsourcing, exchange of } \\
\text { knowledge in (IT) committees }\end{array}$ \\
\hline System architecture & $\begin{array}{l}\text { Standards, electronic patient records (EPRs), service level agreements } \\
\text { (SLAs), enterprise application integration (EAI), data protection during } \\
\text { exchange, industry solutions, patient portals }\end{array}$ \\
\hline
\end{tabular}

\section{Conclusion and further research}

In this article, an approach to assess and advance networkability of health care providing organizations was presented. In order to address and support improvement and efficiency of an industry sector that is facing continuously rising costs opposed by increasingly restrained budgets, a holistic view on means to advance an organisation's ability to efficiently engage in and benefit from business partnerships is required. Despite its evaluation being limited to a Swiss context and a limited evaluation of the design results, the presented maturity model contributes to the knowledge base and addresses the problem space by identifying relevant components and detailed factors that determine maturity of networkability for health care providers. This enables development of a methodological framework to assess current state and give directions on advancing networkability maturity based on accepted models for maturity assessment. Hence, the assessment framework may be used for several purposes including to:

- describe how instances of the design objects of networkability (e.g. Portfolio Management, IT strategy and cooperation strategy) of your organisation are related and how they mutually affect each other leading to a more consistent and holistic strategy of the organisation,

- facilitate organisations to improve their networkability based on a structured analysis of issues, decisions, and actions to be considered,

- understand how an initiative to improve maturity of a certain networkability influencing factor interacts and affects other factors,

finally fostering the analysis, development, and deployment of information systems in consistency with strategic and organisational considerations in order to improve networkability of organisations.

While the motivation and evaluation of the design of the presented maturity model are limited to the health care industry, the focus of the presented work lays on 
administrative, i.e. non-medical, processes of health care providers. Therefore, due to the incorporation of accepted, industry-neutral maturity assessment approaches into the networkability maturity model, applicability also to other industries can be suggested. This will be evaluated as part of future work.

In order to further develop the method for enabling assessment or appraisal of a health care providing organisation, future research and evaluation of the designed model is required. An enhancement of the case-study-driven evaluation will enable improvement of the networkability assessment framework, which is imperative to design a relevant and efficient method in compliance with described design science research guidelines. A subsequent longitudinal study involving before/after assessments of organisations that engaged in networkability advancing projects will enable analysis of reliability and validity of the proposed networkability maturity model. In addition, recent work co-authored by one of the authors of this article highlights the importance of contextual factors, such as size of the organisation or coordination form, which influence the weighting of certain components or factors determining maturity (Mettler and Rohner 2009b). Hence future research will also need to be directed towards the identification of such context factors which configure a situational maturity model of networkability.

\section{References}

Afsarmanesh H, Camarinha-Matos LM (2005) A framework for management of Virtual Organization Breeding Environments. In: Camarinha-Matos LM, Afsarmanesh H, Ortiz A (eds) Collaborative networks and their breeding environments (PRO-VE'05). Springer, Boston et al., pp 35-48

Aier S, Winter R (2009) Virtual decoupling for IT/business alignment-conceptual foundations, architecture design and implementation example. Bus Inf Syst Eng 51(2):150-163. doi: 10.1007/s12599-008-0010-7

Alt R, Fleisch E, Werle O (2000) The concept of networkability-how to make companies successful in business networks. In: Hansen HR, Bichler M, Mahrer H (eds) Proceedings of the 8th European Conference on Information Systems (ECIS 2000). Vienna University of Economics and Business Administration, Vienna, pp 405-411

Anderson RA, McDaniel RR Jr (2000) Managing health care organizations: where professionalism meets complexity science. Healthc Manage Rev 25(1):83-92

Blutt MJ (2001) The rise \& fall and ??? of e-health. http://www.upenn.edu/ldi/healthpolicyseminar jan26_Jan.\%2022\%20\%2701.ppt. Accessed 06 Apr 2009

Braun von Reinersdorff A (2007) Strategische Krankenhausführung-Vom Lean Management zum Balanced Hospital Managment. Verlag Hans Huber, Bern

Briggs RO, De Vreede G-J, Nunamaker JF Jr (2003) Collaboration engineering with ThinkLets to pursue sustained success with group support systems. J Manage Inf Syst 19(4):31-64

Brinkkemper S (1996) Method engineering-engineering of information systems development methods and tools. Inf Softw Technol 38(4):275-280. doi:10.1016/0950-5849(95)01059-9

Bundesamt für Gesundheit (2007) Strategie "eHealth" Schweiz. Eidgenössisches Department des Inneren (EDI). http://www.bag.admin.ch/themen/krankenversicherung/04108/index.html?lang =de\&download=M3wBUQCu/8ulmKDu36WenojQ1NTTjaXZnqWfVpzLhmfhnapmmc7Zi6rZnqC kkIZ3g3iBbKbXrZ2lhtTN34al3p6YrY7P1oah162apo3X1cjYh2+hoJVn6w==. Accessed 06 Apr 2009

Cain MW, Burton B (2005) Evaluate your collaboration maturity to maximize business value, G00128209. Gartner. http://www.gartner.com/DisplayDocument?id=483690\&ref=g_sitelink. Accessed 06 Apr 2009

Camarinha-Matos LM, Afsarmanesh H (2005) Collaborative networks: a new scientific discipline. J Intell Manuf 16(4-5):439-452. doi:10.1007/s10845-005-1656-3 
Chen D (2006) Enterprise interoperability framework. In: Missikoff M, Nicola AD, D'Antonio F (eds) Proceedings of the EMOI-INTEROP'06, enterprise modelling and ontologies for interoperability. Luxembourg, pp 1-5

CMMI Product Team (2006) CMMI for Development, Version 1.2, CMU/SEI-2006-TR-008 ESC-TR2006-008. Software Engineering Institute, Carnegie Mellon University, Pittsburgh

Crosby PB (1979) Quality is free-the art of making quality certain. McGraw-Hill, New York

Curtis B, Hefley WE, Miller SA (2001) People capability maturity model (P-CMM), CMU/SEI-2001MM-001. Software Engineering Institute, Carnegie Mellon University, Pittsburgh

de Vreede G-J, Briggs RO (2005) Collaboration engineering: designing repeatable processes for highvalue collaborative tasks. In: Proceedings of the 38th Annual Hawaii International Conference on System Sciences (HICSS'05). Computer Society Press, Big Island, pp 17-26

Evermann J (2005) Towards a cognitive foundation for knowledge representation. Inf Sys J 15:147-178

Fahrenkrog S, Abrams F, Haeck WP et al (2003) Project Management Institute's Organizational project management maturity model (OPM3). In: Proceedings of the PMI North American Congress 2003. Project Management Institute, Baltimore, pp 1-7

Farsi M, Filippini M (2006) An analysis of efficiency and productivity in swiss hospitals. Swiss J Econ Stat $142(1): 1-37$

Fettke P, Loos P (2003) Multiperspective evaluation of reference models-towards a framework. In: Jeusfeld M, Pastor O (eds) Proceedings of the ER 2003 Workshops ECOMO, IWCMQ, AOIS, and XSDM. Springer, Chicago, pp 80-91

Fettke P, Loos P, Zwicker J (2005) Business process reference models: survey and classification. In: Kindler E, Nüttgens M (eds) Proceedings of the Third International Conference on Business Process Management. University of Paderborn and Universität Hamburg, Nancy, pp 1-15

Fraser P, Moultrie J, Gregory M (2002) The use of maturity models/grids as a tool in assessing product development capability. In: Proceedings of the IEEE International Engineering Management Conference, 2002 (IEMC 2002). IEEE Engineering Management Society, Cambridge, pp 244-249

Frießem P, Kalmring D, Reichelt P (2005) Lösungsarchitektur für die Einführung der elektronischen Gesundheitskarte und der auf ihr basierenden Anwendungen. Wirtschaftsinformatik 47(3):180-186

Gericke A, Rohner P, Winter R et al (2006) Networkability in the Health Care Sector-necessity, measurement and systematic development as the prerequisites for increasing the operational efficiency of administrative processes. In: Spencer S, Jenkins A (eds) Proceedings of the ACIS 2006. Australasian Association for Information Systems, Adelaide, pp 1-10

Gibson CF, Nolan RL (1974) Managing the four stages of EDP growth. Harv Bus Rev 52(1):76-88

Glouberman S, Mintzberg H (2001) Managing the care of health and the cure of disease-Part I: Differentiation. Healthc Manage Rev 26(1):56-69

Henderson JC, Venkatraman N (1993) Strategic alignment: leveraging information technology for transforming organizations. IBM Syst J 32(1):4-16

Hevner AR, March ST, Park J et al (2004) Design science in information systems research. MIS Q 28(1):75-105

Kwak YH, Ibbs CW (2002) Project management process maturity (PM) ${ }^{2}$ model. J Manage Eng 18(3):150-155. doi:10.1061/(ASCE)0742-597X(2002)18:3(150)

Lenz R, Beyer M, Meiler C et al (2005) Informationsintegration in Gesundheitsversorgungsnetzen. Inf Spektrum 28(2):105-119. doi:10.1007/s00287-005-0467-4

Lockamy A III (2004) The development of a supply chain management process maturity model using the concepts of business process orientation. Supply Chain Manage Int J 9(4):272-278. doi: $10.1108 / 13598540410550019$

Luftman JN (ed) (1996) Competing in the information age: strategic alignment in practice. Oxford University Press, New York

Luftman JN (2000) Assessing business-IT alignment maturity. Commun ACM 4(14):1-10

March ST, Smith GF (1995) Design and natural science research on information technology. Decis Support Syst 15(4):251-266. doi:10.1016/0167-9236(94)00041-2

Melenovsky MJ, Sinur J (2006) BPM maturity model identifies six phases for successful BPM adoption, G00142643. Gartner. http://www.gartner.com/DisplayDocument?id=497289. Accessed 06 Apr 2009

Mettler T, Rohner P (2009a) An analysis of the factors influencing networkability in the healthcare sector. Health Serv Manage Res (accepted for publication)

Mettler T, Rohner P (2009b) Situational maturity models as instrumental artifacts for organizational design. In: Proceedings of the 4th international conference on design science research in information systems and technology. ACM, Philadelphia, pp 1-9 
Mettler T, Rohner P, Winter R (2007) factors influencing networkability in the health care sectorderivation and empirical validation. In: Bath P, Albright K, Norris T (eds) Proceedings of the 12th International symposium for Health Information Management Research, University of Sheffield, Centre for Health Information Management Research, Sheffield, pp 51-62

Ontario Hospital eHealth Council (2001) An eHealth blueprint: setting the course for action. http://www.oha.com/oha/reports.nsf/(\$Att)/pspr55vmtq/\$FILE/

eHealthBlueprintDecember2001.pdf?OpenElement. Accessed 06 Apr 2009

Österle H, Winter R (2003) Business engineering. In: Österle H, Winter R (eds) Business engineeringAuf dem Weg zum Unternehmen des Informationszeitalters, 2nd edn. Springer, Berlin, pp 3-19

Österle H, Fleisch E, Alt R (2001) Business networking: shaping collaboration between enterprises. Springer, Berlin

Owen CL (1998) Design research—building the knowledge base. Stud (Roma) 19(1):9-19

Paulk MC, Curtis B, Chrissis MB et al (1993a) Capability Maturity Model(SM) for Software, Version 1.1, CMU/SEI-93-TR-024, ESC-TR-93-177. Software Engineering Institute, Carnegie Mellon University, Pittsburgh

Paulk MC, Weber CW, Garcia SM et al (1993b) Key practices of the capability maturity model, Version 1.1, CMU/SEI-93-TR-025, ESC-TR-93-178. Software Engineering Institute, Carnegie Mellon University, Pittsburgh

Peffers K, Tuunanen T, Gengler CE et al (2006) The design science research process: a model for producing and presenting information systems research. In: Proceedings of the First International Conference on design science research in information systems and technology. Claremont Graduate University, Claremont, pp 83-106

Pennypacker JS (2005) Project portfolio management maturity model. Center for Business Practices, Havertown

Project Management Institute (ed) (2003) Organizational project management maturity model (OPM3): knowledge foundation. Project Management Institute, Newtown Square

Renken J (2004) Developing an IS/ICT management capability maturity framework. In: Marsden G, Kotze P, Adesina-Ojo A (eds) Proceedings of the 2004 annual research conference of the South African institute of computer scientists and information technologists on IT research in developing countries. South African Institute for Computer Scientists and Information Technologists, Stellenbosch, pp 53-62

Rosemann M, de Bruin T (2004) Application of a holistic model for determining BPM maturity. In: Akoka J, Comyn-Wattiau I, Favier M (eds) Proceedings of the AIM pre-ICIS workshop on process management and information systems. Association Information and Management, Washington, pp $1-21$

Rosemann M, de Bruin T, Freeze R, Kulkarni U (2005) Understanding the main phases of developing a maturity assessment model. In: Proceedings of the 16th Australasian conference on information systems (ACIS 2005), Sydney, pp 1-10

Rüegg-Stürm J (2005) The New St. Gallen management model: basic categories of an approach to integrated management. Palgrave Macmillan, Basingstoke

Santanen E, Kolfschoten G, Golla K (2004) The collaboration engineering maturity model. In: Proceedings of the 39th Annual Hawaii International Conference on System Sciences (HICSS 2006). Kauai, pp 1-16

Schwarze J-C, Tessmann S, Sassenberg C et al (2005) Eine modulare Gesundheitsakte als Antwort auf Kommunikationsprobleme im Gesundheitswesen. Wirtschaftsinformatik 47(3):187-195

Simon HA (1969) The sciences of the artificial. MIT Press, Cambridge

Simpson JA, Weiner ESC (1989) The Oxford English dictionary. Oxford University Press, Oxford

Slembeck T (2006) Kostentreiber im Schweizer Gesundheitswesen - Eine Auslegeordnung. University of St. Gallen and Zurich University of Applied Sciences Winterthur, St. Gallen and Zurich

Tapia RS, Daneva M, van Eck P (2007) Validating adequacy and suitability of business-IT alignment criteria in an inter-enterprise maturity model 202. In: Proceedings of the EDOC '07: Proceedings of the 11th IEEE International Enterprise Distributed Object Computing Conference, IEEE Computer Society, Washington, DC, pp 202-213

Teubner A (2006) IT/Business alignment. Wirtschaftsinformatik 48(5):368-371. doi:10.1007/s11576006-0082-2

The Department of Commerce-Enterprise IT Architecture Advisory Group (2003) IT architecture capability maturity model. Department of Commerce, Washington 
Tsikriktsis N (2005) A review of techniques for treating missing data in OM survey research. J Oper Manage 24(1):53-62. doi:10.1016/j.jom.2005.03.001

van der Raadt B, Hoorn JF, van Vliet H (2005) Alignment and maturity are siblings in architecture assessment. In: Pastor O, Falcão e Cunha J (eds) Proceedings of the 17th Conference on Advanced Information Systems Engineering (CAiSE'05). Springer, Berlin, pp 357-371

Venable JR (2006) T The role of theory and theorising in design science research. In: Chatterjee S, Hevner A (eds) Proceedings of the DESRIST 2006. Claremont Graduate University, Claremont, pp $1-18$

Weisbrod BA (1991) The health care quadrilemma: an essay on technological change, insurance, quality of care, and cost containment. J Econ Lit 29(2):523-552

Wigand RT, Picot A, Reichwald R (1997) Information, organization and management-expanding markets and corporate boundaries. Wiley, Chichester 